\title{
Self-Regulated Learning and Academic Achievement of Physics Students in Selected Secondary Schools in Aguata Local Government Area of Anambra State, Nigeria
}

\author{
Theresa Ugonwa Okafor ${ }^{*}$ \\ Departmen ce Education, Chukwuemeka Odumegwu Ojukwu University, Uli, Anambra State, 432108, Nigeria
}

\begin{tabular}{l} 
A R T I C L E I N F O \\
\hline Article history: \\
Received: 07 October, 2021 \\
Accepted: 05 December, 2021 \\
Online: 07 January, 2022 \\
\hline Keywords: \\
Self-regulated learning \\
Students' Academic Success \\
Physics
\end{tabular}

A B S T R A C T
The research investigated the consequence of self-regulated learning on students'academic
performance in physics, using selected public co-education schools in Aguata Educational
Zone, Anambra State as the research area. The study became necessary as a result of the
observed persistent poor performance of the student in Physics in external examinations over
the years. The study made use of quasi-experimental research design method. The research
information was gathered from the control and experimental groups and was investigated
by mean, standard deviation and ANCOVA. The tests were conducted at 0.05 significant
levels. The results showed that students taught using self-regulated learning strategy had
more impressive mean success scores than those taught using conventional method. The
result revealed also that there was no substantial difference between the mean success scores
of the male and female students. However, there was substantial difference in the mean
scores of rural and urban students in favour of rural students. The interaction effects of
strategy and gender on one hand and strategy and location on the other hand, were not
statistically significant. The research concluded that self-regulated learning strategy has
great impact on students' mean success scores in physics.

\section{Introduction}

Self-regulated learning is the capability to comprehend and exert influence on the learner's environment [1]. Self-regulation talents include objective setting, self-instruction, self-monitoring and self-reinforcement, according to the researchers. However, they quickly added that this should not be mistaking for intelligence or academic excellence; rather, self-regulation should be viewed as a process and collection of behaviors that are selfdirected through which learners convert their mental facilities into skills. In their individual efforts, [2] and [3] noted that habit, which comes as a result of guided practice and feedback, is one of the features of self-regulation. In their self-regulated learning research in the classroom, [4] agreed wholeheartedly with the preceding position.

Self-regulated learning (SRL) is a major characteristic of selfregulation that is strongly associated with educational objectives [5]. It is, in their perspective, about metacognition (discerning about one's own reasoning), tactical approach (planning, monitoring, and evaluating personal growth against a specified benchmark), and drive to acquire knowledge. In more formal

\footnotetext{
*Corresponding Author: Theresa Ugonwa Okafor, teresaokafor@gmail.com
}

terms, self-regulated learning has three primary constituents: cognition, metacognition, and motivation [6], as [5] have already stated that self-regulated learning is contained within the domain of self-regulation. He continued by emphasizing that the cognition component covers the abilities and behaviors that are crucial when encoding, learning, and recalling information, as well as critical thinking. The metacognition component is made up of skills that allow students to comprehend and follow-up their own cognitive processes while learning. Motivation encompasses the thoughts and approaches that influence the usage and advancement in both cognitive and metacognitive skills [7]. It's no surprise that selfregulated learners tackle tough problems and put their learning activities into practice, gain a thorough comprehension of the problem at hand, and put in the work required to achieve academic achievement [5]. Self-regulated learners frequently exhibit feeling of ego to some extent as a result of these features. However, in the psychology education literature, scholars have attempted to link these qualities to achievements in and outside school

Physics, on the other hand, as one of the basic secondary school science disciplines, has proven to be a difficult hurdle for students to overcome in both internal and external examinations over the years. Nonetheless, the subject is one of the most important 
scientific subjects, as it is essential for the global growth of science and technological advances [8]. As a science or course of study that deals with natural phenomena, it aids man in understanding the nature and structure of the universe by studying the nature of matter and energy. It's no surprise that science education programs in Nigeria were created to aid students in learning problem-solving and decision-making abilities, as well as discover the interconnectedness of various science subjects, such as the relationship between physics and health, agriculture, industry, and technology, among others, in a variety of fields.

Given the importance of science education in any economy, the Nigerian government has made a concerted effort to improve science educational methods in schools. This has been accomplished through the government acquiring science equipment and hiring teachers with experience in related fields, as well as providing, to some extent, an enabling environment for students to learn without being distracted. However, students' performance in science topics, especially physics, has continued to be dismal in both internal and external examinations. Following this, concerned citizens have speculated that the method of teaching and learning physics and other science subjects may be to blame for the outcomes seen in the area. More specifically, it has been observed that most physics teachers' teaching methods do not allow students to effectively participate in class lessons, thereby limiting the rate of learning and retention in the subject. As a result, it has been suggested that introducing a learning strategy that encourages students to take charge of their learning process via a self-regulated approach may be more effective in increasing their comprehension and retention rate [8].

\subsection{Statement of the Problem}

Despite governments' concerted efforts directed at improving students' performance in physics results, students have continued to show dismal performance in physics external examinations such as WAEC, NECO and JAMB. This is evident from the last results of the subject at least from $2007-2018$ where those who passed physics subject at credit level in those examinations were below 50 percent of those who enrolled in the mentioned years (WAEC, 2019). The situation has become really worrisome given the expected role and importance of physics as one of the basic sciences in the economy of Nigeria. Consequently, the research problem can be modeled as a question as follows: How can selfregulated learning mode be the answer to students' poor performance in secondary school physics?

\subsection{Objectives of the Research}

The main objective of the research is to survey the consequence of self-regulated learning on academic achievement of secondary school students in physics by using selected co-educational schools in Aguata Educational Zone of Anambra State, Nigeria as the research area. However, the specific objectives are to:

(i) investigate the influence of self-regulated and conventional learning on students' mean success scores in physics.

(ii) survey the consequence of gender on students' mean physics success scores when taught by self-regulated learning technique. (iii) determine the effect of school location on students' average success scores in physics when taught by self-regulated learning method.

(iv) evaluate the interaction effects of method and gender on students' mean success scores in physics.

(v) ascertain the interaction effects of method and location on students' mean success scores in physics.

\subsection{Research Questions}

The following research questions were raised to guide the study:

(i) How do self-regulated and conventional learning methods affect the students' mean achievement scores in physics?

(ii) What is the impact of gender of students' on average success scores in physics when taught by self-regulated learning method?

(iii) What is the effect of school location on students' average success scores in physics when taught by self-regulated learning method?

(iv) What is the interaction consequence of self-regulated learning method and gender on students' average success scores in physics?

(v) What is the interaction consequence of self-regulated learning method and location on students' average success scores in physics?

\subsection{Statement of Hypotheses}

The following null hypotheses were articulated to direct the objectives of the research and fortify the analysis:

(i) There is no substantial difference in the average success scores of students taught physics by self-regulated and conventional learning methods.

(ii) There is no substantial difference between the average success scores of male and female students taught physics by self-regulated learning method.

(iii) There is no substantial difference in the average success scores of urban and rural student taught physics by selfregulated learning method.

(iv) There is no substantial interaction consequence of method and gender on students' average success scores in physics.

(v) There is no substantial interaction consequence of method and location on students' average success scores in physics.

\subsection{Significance of the Research}

The study is important from both a theoretical and empirical pespective. From a theoretical standpoint, the study will greatly contribute to the current body of literature in this field of research, thereby broadening the boundaries of knowledge. Empirically, both the teachers and the students will benefit greatly from the outcomes of the research. The teachers would be given insight on how to make use of self-regulated learning techniques for better imparting of knowledge in physics subjects. Similarly, the students would be enlightened on how to utilize self-regulated learning approach to accomplish great tasks in their academic endeavours 


\subsection{Scope of the Research}

The research covers Aguata Educational Zone, Anambra State. Two co-educational secondary schools were purposefully selected namely, St Paul's Academy secondary school Ekwulobia and thus reflecting urban and rural mix respectively. In terms of variable scope, the study focuses on likely influence of self-regulated learning method on students' performance in physics subject.

\section{Literature review}

\subsection{Conceptual Review}

Regulatory education has been described as a background variable that refers to how much the teaching process encourages and outwardly helps students' self-regulated learning. It has been termed a meta-instructional variable that promotes student selfregulation and possesses hallmarks of efficient teaching [9]. But more formally, self-regulated learning has been defined as anything students engaged in order to organize and follow up their learning process, as well as to diagnose the source of any difficulties that arise while learning and design strategies to overcome it and move towards the learning objectives set initially as yardstick [2].

On the other hand, academic success as a determinate and consequence of the educational process in such a way that the degree, magnitude or level of learning aftermaths of students at various levels of education are direct effect of the teaching method [10]. It is further defined as the level to which a single student has gained information, abilities, and experiences in a certain set of academic goals [11]. However, within the context of this study, the concept is taken as the scores of individual students in physics examinations. It includes also, students' performance in tests and assignments [12].

\subsection{Theoretical Framework}

The study is based on Structuralist Theory, which was established by [13], and Bandura's Social Cognition Theory of Self-regulation [14]. Structuralists consider learning to be a selfregulated method in which students increase their ability to learn through the selective use of techniques. To that purpose, students monitor, control, or manage parts of their own cognition, motivation, and conduct, as well as some characteristics of their surroundings. Bandura's Social Cognition Concept of SelfRegulation posits that students have objectives and that during their learning activities, they observe, judge, and react to their views of goal processes. In his opinion, self-regulation is a selfdirected method which aid the students to translate their mental aptitudes into academic capacities. The framework of the two theories above has demonstrated that if students effectively utilize motivation strategies in their studies, their learning outcomes will be enhanced substantially.

\subsection{Theoretical Exposition}

Self-regulated learning tactics assist students in readiness for enduring learning and acquiring crucial capabilities such as the ability to transfer skills, information, and talents from one area or context to another. This shows that it is a key method in the learning process at both the fundamental and advanced levels [15]. They observe that it is a cognitive learning approach strategy, and its application in learning has a substantial positive link with users' academic accomplishment. Students are more inspired to learn and are very likely to succeed when they apply a consolidation of academic learning skills and self-control that enables learning simpler [16]. In [10], the authors noted also that those students who are self-regulated in learning, metacognitive, motivated equally conduct themselves in a decent manner as well as offer initiative and direction for their own endeavors to learn information and skills without the assistance of teachers, parents, or others. Selfregulated learning is a recurring method that comprises of planning, execution, monitoring, and self-evaluation, which is used as feedback to achieve improved performance by students in their class works [2].

Self-regulated learners exhibit motivated beliefs as well as adaptive emotions such as academic self-efficacy [17]. The author noted further that such learners adopt learning goals and develop positive emotion towards tasks (example: joy, satisfaction and enthusiasm). Such learners, in his option, also have the capability to regulate and change them in accordance with the requirements of pre-set activities and various learning situations [18]. Selfregulated learners plan and control the time and effort spent on assignments, and they understand how to create and structure favorable situations, such as locating an appropriate study location and asking assistance from teachers and peers when challenges arise. This set of people make stronger efforts to regulate academic activities, classroom climate, and structure, which affect a number of volitional tactics aimed at avoiding external and internal distractions so that they can retain their concentration, effort, and motivation in doing tasks [17]. Therefore, self-regulated learners are those who are metacognitively, motivationally, and behaviorally involved in their own learning progressions and goal attainment [19].

\subsection{Empirical Review}

In [16], the authors conducted a research to determine the influence of self-regulated learning on students' mathematics success, it could be seen that self-regulated learning actually has substantial consequence on mathematics success because it makes the learning process very effective. The finding has indicated that students with strong self-regulated learning are likely to be highly motivated and successful in any topic, and vice versa. In another study carried out by [20], to verify the likely effects of selfregulated learning on the success of students in physics subject in secondary schools, using quasi-experimental and control groups, the data analysis utilizing the t-test revealed that students that practiced self-regulated learning outperformed those who did not engage in self-regulated learning.

In a research conducted by [21] to investigate the influence of self-regulated learning approach in the basic science successes of students in junior secondary school, quasi-experimental design was used. Findings from study show that students' performance in basic science improved significantly using a self-regulated learning method as against traditional approach. In a related study, [22] investigated the impact of self-regulated learning tactic on achievements of the students in basic sciences in Makurdi Council Area, Benue State, Nigeria. The research used the non-equivalent group pretest-posttest quasi-experimental method. Results of the research revealed that demonstration method improved the 
achievements of students of basic science more than self-regulated approach. Secondly, no statistical substantial difference in average achievement in scores were recorded between students taught basic science by self-regulated learning technique and those taught by demonstration technique. Thirdly, average success scores of students of different gender taught basic science utilizing a selfregulated learning technique did not differ significantly. The study concludes that combination of self-regulated learning tactic and demonstration technique would produce a better student.

In another study, the researcher investigated the relationship between academic motivation and self-regulated learning in predicting academic accomplishment in school [23]. The data for the study were collected with the help of the academic motivation scale [24], and the academic self-regulated learning scale. The findings revealed that there was no correlation between average grade points and academic motivation and self-regulated learning. It means that, the combined scores of academic motivation and self-regulated learning did not determine the students' average grade points.

\section{Methodology}

\subsection{Research Design}

Quasi-experimental design was implemented in this research, which permitted the use of intact classes to circumvent the disruption of the usual class lessons. Furthermore, pre-test was also utilized to remove early variances in the two groups and to minimize selection prejudice which is a threat to core validity.

Illustrated below elucidate the design:

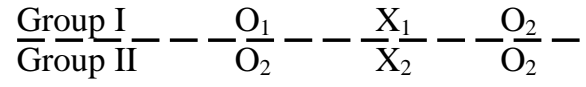

Where:

$\begin{array}{lll}\mathrm{O}_{1} & = & \text { Pre-test } \\ \mathrm{X}_{1} & = & \text { treatment for Experimental Group } \\ \mathrm{X}_{2} & = & \text { Control group } \\ \mathrm{O}_{2} & = & \text { Post test }\end{array}$

\subsection{Area of the Research}

Non-private secondary schools in Aguata Council Area of Anambra State were used for this research. Specifically, St Paul's Academy Secondary School, Ekwulobia and Community Secondary School, Achina, both in Aguata L.G.A.

\subsection{Research Population}

The population of the research consists of the 1,356 Senior Secondary Two (SS II) Physics students in the two co-educational schools selected for the research. Since gender is one of the considerations, co-educational schools were studied. There is also issue of the location hence the rural-urban mix in the selection of schools in the study. We have also used the SS II intact classes because they are not in any external examination.

\subsection{Instrument for Data Collection}

Physics Achievement Test (PAT) is the tool utilized for data collection in this study. Items for PAT consists of twenty (20) multiple choice questions in tandem with the secondary school Physics curriculum and was culled from the West African
Examination Council (WAEC). The PAT was used to assess the students' achievement in Physics.

\subsection{Experimental Procedure}

The researcher trained the teachers selected for control and experimental groups. While teachers for the experimental group were trained on guiding the students on self-regulated learning, the teachers for the control group were mentored on how to use the conventional method. Preceding the start of the experiment, the students were given a pre-test. PAT was given to the subjects for both the treatment and control groups at the end of the experiment by the teachers to answer and after that, the scripts were collated and scored and the results were used for the analysis.

\subsection{Method of Data Collection}

After the treatment session, posttest was conducted for the students and the results for both control and experimental groups were collated for investigations in order to answer the initial research questions and verify the claims of the null hypothesis.

\subsection{Method of Data Analysis}

Whereas mean $(\bar{x})$ and standard deviation (SD) were employed to answer the research questions, analysis of covariance (ANCOVA) was utilized to verify the hypotheses at 5 percent level of significance.

\section{Data presentation and analysis}

\subsection{Answer to Research Questions}

Table 1: $\quad$ Mean $(\bar{x})$ and Standard Deviation (SD) of Effect of Self-regulated Learning on Students Average Success Scores in Physics

\begin{tabular}{|c|c|c|c|c|c|c|}
\hline \multirow[t]{2}{*}{ Method } & \multirow[t]{2}{*}{$\mathrm{N}$} & \multicolumn{2}{|c|}{ Pretest } & \multicolumn{2}{|c|}{ Posttest } & \multirow{2}{*}{$\begin{array}{c}\text { Gained Score } \\
\overline{\mathrm{x}}_{\mathrm{g}}\end{array}$} \\
\hline & & $\overline{\mathrm{x}}_{1}$ & $\mathrm{SD}_{1}$ & $\overline{\mathrm{x}}_{2}$ & $\mathrm{SD}_{1}$ & \\
\hline $\begin{array}{l}\text { Self- } \\
\text { regulated }\end{array}$ & 71 & 10.58 & 4.30 & 23.85 & 5.76 & 13.27 \\
\hline Conventional & 74 & 7.87 & 3.75 & 18.61 & 6.43 & 10.74 \\
\hline
\end{tabular}

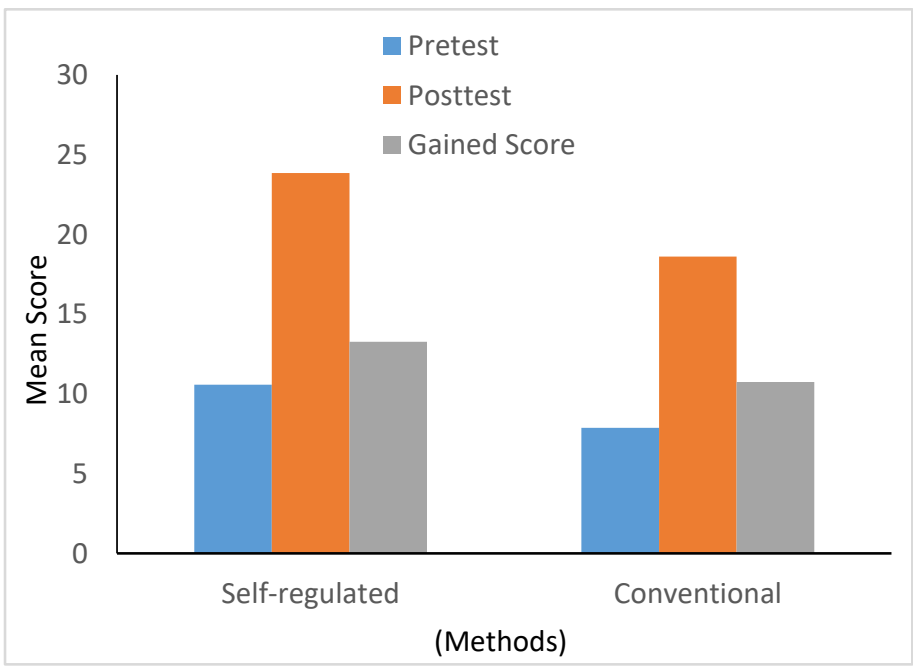

Figure 1: Mean Scores for self-regulated and conventional methods of teaching in both Pretest and Posttest

As could be seen from Table 1, the students taught using selfregulated tactic has an average score of 23.85 while those with the 
conventional method is 18.61 with a gained score of 13.27 and 10.74 respectively thus showing that the students taught using SRL strategy out-performed those who were taught through conventional method.

Table 2: Mean $(\bar{x})$ and Standard Deviation (SD) of Effect of Gender on Students' Success in Physics based on SRL Strategies

\begin{tabular}{lcccccc}
\hline Gender & \multirow{2}{*}{} & \multicolumn{2}{c}{ Pretest } & \multicolumn{2}{c}{ Posttest } & Gained Score \\
\cline { 3 - 6 } & & $\overline{\mathrm{x}}_{1}$ & $\mathrm{SD}_{1}$ & $\overline{\mathrm{x}}_{2}$ & $\mathrm{SD}_{1}$ & $\overline{\mathrm{x}}_{\mathrm{g}}$ \\
\hline Male & 84 & 10.91 & 4.32 & 21.14 & 5.75 & 10.23 \\
Female & 61 & 9.20 & 3.85 & 20.01 & 6.22 & 10.81 \\
\hline
\end{tabular}

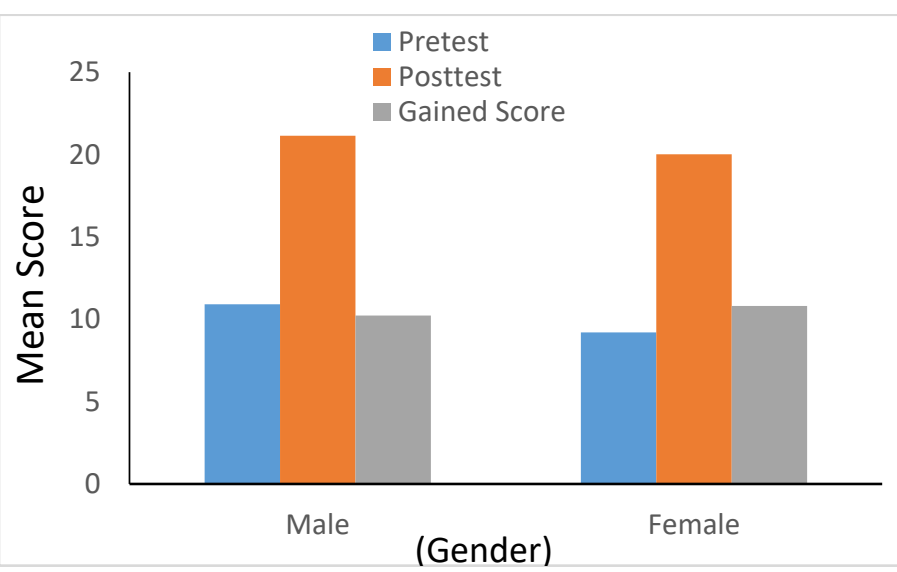

Figure 2: Mean Score for Male and Female Students in both Pretest and Posttest

The mean and standard deviation analysis presented in Table 2 reveals that the male students' average success score is 21.14 whereas that of their female counterparts is 20.01 thus showing that male students marginally did better than the female students. However, in terms of gained scores, female achieved mean was equally marginally higher than the males.

Table 3: Mean $(\bar{x})$ and Standard Deviation (SD) of Effect of Location on Students' Average Success Score in Physics when Teaching was carried out through SRL Method

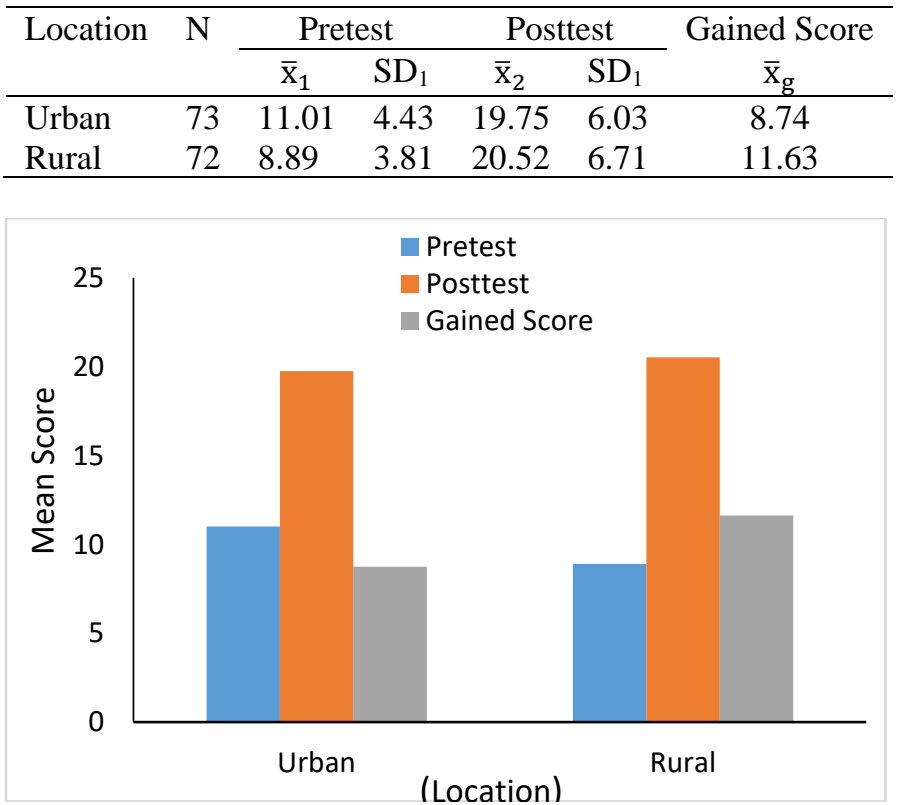

Figure 3: Mean Score for the Students in Urban and Rural Schools for both Pretest and Posttest
The results of mean and standard deviation presented in Table 3. The analysis showed that 19.75 is the average success score for urban students and 20.52 is the average success score for the ruralbased students. Similarly, whereas urban students gained mean score of 8.74, the rural-based students gained mean score of 11.63 thus showing that rural-based learners did better than the urbanbased learners in the test.

Table 4: Mean $(\bar{x})$ and Standard Deviation (SD) of Success Scores by Strategy and Gender

\begin{tabular}{|c|c|c|c|c|c|c|}
\hline \multirow{2}{*}{$\begin{array}{l}\text { Gender/Strategy } \\
\text { Pretest }\end{array}$} & \multicolumn{3}{|c|}{$\begin{array}{l}\text { Self-regulated } \\
\text { Learning }\end{array}$} & \multicolumn{3}{|c|}{ Conventional } \\
\hline & $\mathrm{N}$ & $\overline{\mathrm{x}}$ & SD & $\mathrm{N}$ & $\overline{\mathrm{X}}$ & $\mathrm{SD}$ \\
\hline Male & 57 & 10.85 & 4.21 & 27 & 7.89 & 4.00 \\
\hline Female & 12 & 8.93 & 3.87 & 49 & 8.05 & 3.90 \\
\hline \multicolumn{7}{|l|}{ Posttest } \\
\hline Male & 57 & 22.46 & 4.28 & 27 & 17.07 & 7.54 \\
\hline Female & 12 & 23.57 & 6.26 & 49 & 19.45 & 7.38 \\
\hline $\begin{array}{l}\text { Observed } \\
\text { and (SD) }\end{array}$ & & 23.85 & 5.76 & & 18.61 & 6.43 \\
\hline
\end{tabular}

From Table 4, the average success score for the male students who were taught using self-regulated method is 22.46 while that of the female is 23.57 . Similarly for the male students taught using conventional method, it is 17.07 and 19.45 for the female. However, the findings do not indicate ordinal interaction effect between tactic of teaching and gender of students. As could be seen, for different gender, the mean scores for the SRL method were higher.

Table 5: Mean $(\bar{x})$ and Standard Deviation (SD) of Success Scores by Strategy and Location

\begin{tabular}{llcllcl}
\hline Location/Strategy & \multicolumn{2}{l}{$\begin{array}{l}\text { Self-regulated } \\
\text { Learning }\end{array}$} & \multicolumn{4}{c}{ Conventional } \\
\cline { 2 - 7 } Pretest & $\mathrm{N}$ & $\overline{\mathrm{x}}$ & $\mathrm{SD}$ & $\mathrm{N}$ & $\overline{\mathrm{x}}$ & $\mathrm{SD}$ \\
\hline Urban & 50 & 10.97 & 4.23 & 23 & 8.54 & 4.14 \\
Rural & 21 & 8.41 & 3.61 & 51 & 7.65 & 3.85 \\
Posttest & & & & & & \\
Urban & 50 & 22.49 & 4.35 & 23 & 16.45 & 7.5 \\
Rural & 21 & 22.45 & 5.41 & 51 & 19.65 & 7.27 \\
\hline Observed $(\overline{\mathrm{x}})$ and & & 23.85 & 5.76 & & 18.61 & 6.43
\end{tabular}

(SD)

The analysis in Table 5 revealed that average score for urban students taught using SRL strategy, is 22.49 while their rural counterparts is 22.45 . Similarly, the average score of the urban students taught with conventional method is 16.45 while that of the rural students is 19.65 . As could be seen, the results indicate ordinal interaction effect between strategy of teaching/learning and location of students.

\subsection{Test of Hypotheses}

All the hypotheses formulated to direct and strengthen the analysis were tested in this section through the application of Covariance technique known as analysis of covariance (ANCOVA). The result is presented in Table 6.

Table 6: Analysis of Covariance of Students Mean Achievement Scores in Physics Test

\begin{tabular}{llllll}
\hline $\begin{array}{l}\text { Source of } \\
\text { Variation }\end{array}$ & $\begin{array}{l}\text { Sum of } \\
\text { Squares }\end{array}$ & df & Mean & F & Sig. \\
\hline
\end{tabular}




\begin{tabular}{llllll}
\hline Covariate & 1650.842 & 8 & 206.355 & 6.615 & .000 \\
Model & & & & & \\
Intercept & 4387.341 & 1 & 4387.341 & 140.642 & .000 \\
Pretest & 457.145 & 1 & 457.145 & 14.654 & .000 \\
Method & 185.704 & 1 & 185.704 & 5.953 & .017 \\
Gender & 68.302 & 1 & 68.302 & 2.189 & .145 \\
Location & 215.87 & 1 & 215.87 & 6.920 & .012 \\
$\begin{array}{l}\text { Method by } \\
\text { Gender }\end{array}$ & 6.585 & 1 & 6.585 & 0.211 & .654 \\
$\begin{array}{l}\text { Method by } \\
\text { Location }\end{array}$ & 59.125 & 1 & 59.125 & 1.895 & .177 \\
$\begin{array}{l}\text { Gender by } \\
\text { Location }\end{array}$ & 18.897 & 1 & 18.897 & 0.606 & .460 \\
Method by & 122.524 & 1 & 122.524 & 3.928 & .056 \\
$\begin{array}{l}\text { Gender by } \\
\text { Location }\end{array}$ & & & & & \\
$\begin{array}{l}\text { Error } \\
\text { Total }\end{array}$ & 4242.571 & 136 & 31.195 & - & - \\
Corrected & 57143.01 & 145 & & & \\
Total & 5788.561 & 144 & & & \\
\hline
\end{tabular}

* df(degree of freedom), F (F-ratio) Sig. (significance level).

\subsection{Interpretation of ANCOVA Results}

In this section, the ANCOVA results were interpreted and all tests were carried out at 0.05 level of significance and $\mathrm{f}(1,144)$ degrees of freedom. That being the likely level at which we are willing to accept type I error.

\section{Decision Rule I}

At 0.05 level of significance and $\mathrm{f}(1,144)=5.953, \mathrm{P}<.017$, the null hypothesis was rejected thus showing there is substantial variance in the average success scores of the students taught physics using self-regulated learning tactic and those that used conventional method. The implication is that SRL technique is better than the conventional method of learning physics.

\section{Decision Rule II}

At 0.05 level of significance and $f(1,44)=2.189, P>.145$, the null hypothesis was accepted, and we came to the conclusion that there is no substantial difference between male and female students' average success scores in Physics.

\section{Decision Rule III}

At 0.05 level of significance and $\mathrm{f}(1,144)=6.920, \mathrm{P}<.012$, the null hypothesis was rejected and the alternative accepted and we conclude that there is a significant difference between the average success scores of urban and rural based students in physics.

\section{Decision Rule IV}

At 0.05 , level of significance and $\mathrm{f}(1,144)=.211, \mathrm{P}>.654$, the null hypothesis was accepted thus indicating that the interaction effect of method and gender on students average success scores in physics was not statistically significant.

\section{Decision Rule V}

At 0.05 level of significance and $\mathrm{f}(1,144)=1.895, \mathrm{P}>.177$, the null hypothesis was accepted thus suggesting that the interaction effect of strategy and location on students' average success scores in physics was not statistically significant.

\section{Conclusion}

From the answers obtained from the research questions analysed, gained score for the students who used self-regulated learning method is 13.27 while that of the conventional method is 10.74 thus showing that SRL strategy is superior to conventional method. Similarly from the mean scores of the students as presented in Table 2, it could be seen that male students performed marginally better than their female counterparts. In the same vein, Table 3 showed that rural-based students with average success score of 20.52 did better than the urban-based students with mean achievement score of 19.75. In terms of strategy and gender, at all levels of gender, the mean achievement scores for SRL strategy were higher than the conventional strategy. However, the result did not indicate ordinal interaction. Lastly, the SRL strategy has continued to maintain higher mean achievement scores even amongst the rural based students with a visible ordinal interaction effect strategy and location. The rest of the summary is specifically presented below:

1. The average success scores of students taught using the SRL technique and those taught using the traditional way differ significantly, with the SRL method having the upper hand.

2. In the physics test, there is no major difference in average success scores between male and female students.

3. In the physics test, there is a large disparity between the mean achievement scores of urban and rural based students.

4. There is no statistically significant interaction between strategy and gender on students' average success scores in the physics test.

5. There is no statistically significant interaction between strategy and location on students' average success scores on the physics test.

Furthermore, the fact that there was a marginal increase in the performance of male students over their female counterpart is an indication that both sexes have the opportunity of utilizing SRL strategy to increase performance. Therefore, it has become increasingly important that students should know how to manage their own learning as both the need and the opportunities for individuals to learn on their own outside of formal classroom settings becomes more obvious.

A major finding in this study is that self-regulated learning method is better than the conventional method in the promotion of enhanced academic success for the students. It is a finding that is coherent with previous studies such as $[8,20,21,22]$ that confirmed the significant importance of self-regulated learning to students' development and consequently, improved performance in academic works. This conclusion arose from the respective performance of the students after they were subjected to both pretest and posttest experiments in physics subject, where the selfregulated learning students outperformed the students taught with conventional method.

\section{Recommendations}

The recommendations presented herewith were based on the findings and conclusion of the study:

1. Given the significance difference in the average success scores between students taught using the SRL technique and those taught using the traditional approach in favor of the 
SRL method, we recommend that secondary schools in Nigeria should start using the SRL technique because it has shown to be effective in enhancing students' performance.

2. Teachers in secondary schools should be trained to understand what SRL method is all about so that they provide proper guidance to students on SRL strategy.

3. Orientation exercise should be organized by the stakeholders in education for the students on the strategies of selfregulated learning for better academic achievement in all subjects.

\section{Practical Implications of the Study}

One of the challenges of the study was the limited knowledge of the teachers in self-regulated learning method. In the course of the experiment, it was found that not many teachers in the used schools used have good knowledge of self-regulated learning and it affected in no less measures, the performance of the students in the tests. Other areas of concern were inadequate number of facilities and favourable environment suitable for study. Therefore, there is the need to train the teachers on how to effectively guide the students in self-regulated learning as it has proved to be more successful in improving students' academic performance. Another policy dialogue is in the aspects of provision of necessary facilities that can aid the students to create the enabling and suitable environment for efficient utilization of self-regulated mode of learning which has proved to superior to the conventional mode which happens to be teacher-centered.

\section{References}

[1] G. Schraw, Crippen, K. \& Hartley, K., "Promoting self-regulation in science education: metacognition as part of a broader perspective on learning," Research in Science Education, 36, 111-139, 2006, doi.org/10.1007/s11165005-3917-8.

[2] B. Zimmerman, S. \& Kovach, R., "Developing self-regulated learners: beyond achievement to self-efficacy," Washington D.C. American Psychological Association, 2002, https://doi.org/10.1037/10213-000.

[3] D. Butlar, "Individualizing instruction in self-regulated learning," Theory into Practice, 41, 81-92, 2002, http://www.jstor.org/stable/1477459.

[4] S. Paris, Paris, A., "Classroom applications of research on self-regulated learning," Educational Psychology, 36, 89-101, 2001, https://doi.org/10.1207/S15326985EP3602_4

[5] J. Burman, T. Green, C.D. and Shanker, S., "On the meanings of selfregulation: digital humanities in service of conceptual clarity," Child Development, 86(5), 1507-1521, 2015, DOI: 10.1111/cdev.12395

[6] S. Tanya, "Self-regulated learning," Teaching excellence in adult literacy (TEAL). (enter Fact Sheet No.3), 2017.

[7] E. Alvi, Iqbal, Z., Masood, F. and Batool, T., "A qualitative account of the nature and use of self-regulated learning (SRL) Strategies employed by university Students," Australian Journal of Teachers Education, 41(8), 4059, 2016, DOI 10.14221/ajte.2016v41n8.3

[8] J. Nnaji, Okoli, J.N. "Relationship between self-regulated learning skill and achievement of secondary school students in Physics in Enugu State, Nigeria," JSTME, 3(1), 115-127, 2019,

[9] J. Antonelli, Jolly, S., Backscheider, S. and Hawk in set J., "Understanding the self-regulated learning characteristics of first-generation college students," Journal of College Stud. Dev. 61, 67-83, 2020, dio: 10.1353(sd.2020.0004).

[10] T. York, Gibson, C. and Rankin, S., "Defining and measuring academic success," Practical Assessment, Research and Evaluation, 20(5), 2-12, 2015.

[11] B. Illahi, Y. and Khandai, H., "Academic achievements and study habits of college students of District Pulwama," Journal of Education and Practice, 6(31), 1-16, 2015.

[12] E. Siahi, A. and Maiyo, J.K., "Study of the relationship between study habits and academic achievement of students: a study of Spicer Higher Secondary School, India," International Journal of Educational Administration and Policy Studies, 7(7), 134-141, 2015.

[13] L. Steffe, Gale, J. E. (Eds.), Constructivism in education. Lawrence Erlbaum
Associates, Inc., 1995.

[14] A. Bandura, "Social cognitive theory of self-regulation," Organizational Behavior and Human Decision Processes, 50, 248-287, 1991, https://doi.org/10.1016/0749-5978(91)90022-L

[15] G. Dettori, Donattela, M. and Persico, B., Fostering self-regulated learning through ICT, New York: Hershey, 2011.

[16] A. Fauzi, Widjajanti, D.B., "Self-regulated learning: the effect on students' mathematics achievement," Journal of Physc. Conference Series, 1097, 2018.

[17] I. Banu, "The relationship between self-regulated learning strategies and academic achievement in a Turkish EFL setting," Educational Research Review, 8(17), 1544-1550, 2013.

[18] T. Loong, "International students' self-regulated learning and its relation to mathematics achievement in an offshore Australian Program," Academic Research International, 4(5), 507-520, 2013.

[19] B. Zimmerman, Schunk, D., Self-regulated learning and academic achievement. Theoretical perspective. Mahwah, NJ: Lawrence Eribaum Associates, 2008.

[20] N. Achufusi-Aka, Offiah, F.C., "The effect of self-regulated learning on academic achievement of secondary school physics students," African Journal of Educational Studies in Mathematics and Sciences 8(2), 29-33, 2010.

[21] C.E. Nwafor, Obodo, A.C. and Okafor, G., "Effect of self-regulated learning approach on junior secondary school students' achievement in basic science," Journal of Education and Practice, 6(5), 45-52, 2015.

[22] C.M. Tirgba, Bur, J.I., "Effect of self-regulated learning strategy on students' achievement in basic science in Makurdi Local Government Area, Benue State, Nigeria," African Journal of Teachers Education (AJOTE), 8. 361379, 2019.

[23] B. Cetin, "Academic motivation and self-regulated learning in predicting academic achievement in College," Journal of International Education Research, Second Quarter, 11(2), 95 -106, 2015.

[24] R. Vallerand, Pelletier, L. G., Blais, M. R., Briere, N. M., Senecal, C., and Vallieres, E. F., "The Academic Motivation Scale: a Measure of Intrinsic, Extrinsic, and Amotivation in Education," Educ. Psychol. Meas. 52(4), 1003-1017, 1992, DOI10.1177/0013164492052004025. 